of pregnancies, abortions, still birth, \& intrauterine fetal death, multiple pregnancies, neonatal deaths, infant deaths, \& low birth weight babies.

Results The study included 190 mothers of consanguinous marriage and 320 non consanguinous. there was no statistically significant relation between consanguinity and no of pregnancies, abortions, stillbirths or multiple pregnancies.however there was a statistically significant relation between consanguinity and nneonatal deaths, infant deaths and low birth weight babies.

Conclusion Consanguinity has an adverse effect on pregnancy and neonatal outcome and should be considered as a factor in high risk pregnancy, the neonatologist and obstetrician should be alerted to.

\section{THE RELATIONSHIP BETWEEN MOTHER'S CONDITION AND NEWBORN BIRTH WEIGHT}

doi:10.1136/archdischild-2012-302724.1365

S Gatot-Irawan, A Sunardi, RP Rina-Pratiwi, A Agus-Fitrianto, MS Kosim. Department of Pediatrics, Faculty of Medicine Diponegoro University - Dr. Kariadi Hospital, Semarang, Indonesia

Background Birth weight is a powerful predictor of infant growth, intra uterine welfare and survival. The outcome of birth weight is a reasonable well-defined problem caused by factors that are potentially modifiable. Mother's condition were important risk factor for determining the outcome of birth weight.

Objective To determine the relationship between mother's condition and newborn birth weight

Methods/design Case control study in Dr. Kariadi Hospital Semarang, Indonesia. Data were taken from medical records of babies who fulfilled inclusion criteria and admitted from January 2011 until December 2011. The mother's condition included age, education, parity, nutritional status from Mid Upper Arm Circumference (MUAC), gestational age, antenatal care, (ANC), hypertension, and anaemia. Birth weight was determined at birth with same scale and categorized in to some categories. Statistical analyses used: $\mathrm{X}^{2}$ and logistic regression.

Results We obtained 30 mother of babies with low birth weight as a Case Group and 30 mother of babies/with appropriate birthweight as the control group. We found between groups: MUAC has (OR 0.10 ; 95\% CI:0.01-0.6) p=0.01, anaemia has (OR 0.13; 95\% CI :0.03$0.61) \mathrm{p}=0.09$, and gestational age has (OR 21.76; 95\% CI :3.6-129) $p=0,001$, age has (OR 0.90; 95\% CI :0.19-4.15) $p=0.89$, Hypertension has (OR 0.44; 95\% CI:0.73-2.69) $\mathrm{p}=0.37$, parity has (OR 0.36 ; 95\% CI:0.11-1.20) $\mathrm{p}=009$, education has (OR 0.12; 95\% CI :0.101.60) $\mathrm{p}=0.11$, ANC has (OR 0.01; 95\% CI :0.02-0.6) p=0.99.

Conclusion MUAC, anaemia and gestational age as risk factor of LBW. Gestational age was the most important one.

\section{PERINATAL RISK FACTORS OF INTRAUTERINE GROWTH RETARDATION}

doi:10.1136/archdischild-2012-302724.1366

'S Ali-Zade, 'S Huseynova, ${ }^{2} \mathrm{~N}$ Panakhova, ${ }^{2} \mathrm{~S}$ Hasanov, ${ }^{2} \mathrm{~S}$ Alasgarova, ${ }^{2} \mathrm{H}$ Dunyamaliyeva. ${ }^{1}$ Odlar Yurdu; ${ }^{2}$ Neonatology, Azerbaijan Medical University, Baku, Azerbaijan

Background and Aim Intrauterine growth retardation (IUGR) is a serious health condition that causes significant morbidity and serious developmental problems in children. The aim of this study was the identification of the role of pregnancy complications in the development of growth retardation.

Study Design 210 women with complicated pregnancy and their newborn infants were included in study. Pregnant women were classified depending on different pathologies such as preeclampsia, anemia, somatic diseases and their combinations. IUGR identified in infants whose estimated anthropometrical measurements was below the 10th percentile for its gestational age, and also confirmed using the Dubowitz/Ballard scale.

Results The IUGR was detected in $38.46 \%$ in women with different somatic diseases of pregnancy, in $50 \%$ in women with preeclampsia, $30.30 \%$ in women with different grade of anemia. Highest frequency (66.66\%) of this syndrom was diagnosed in infants whose mothers suffered from both preeclampsia and anemia during pregnancy, and in $33.3 \%$ of these infants determined symmetrical type growth restriction.

Conclusion Preeclampsia is one of the main factor affecting maternal-placental-fetal interactions and it may be accepted as more serious risk factor when associates with anemia in pregnancy.

\section{NEONATAL MOTALITY AND MOBIDITY RATES WHO WERE ADMITTED TO THE NEONATAL ICU OF KONYA IN TWO YEARS}

doi:10.1136/archdischild-2012-302724.1367

${ }^{1} \mathrm{H}$ Altunhan, ${ }^{2} \mathrm{~A}$ Annagür, ${ }^{3} Y U ̈$ Özdemir, ${ }^{3} \mathrm{M}$ Konak, ${ }^{3} \mathrm{R}$ Örs. ${ }^{1}$ Department of Neonatology, Abant Izzet Baysal University, Medical Faculty, Bolu; 'Department of Neonatology, Selcuk University, Selcuklu Medical Faculty; ${ }^{3}$ Department of Neonatology, Konya University, Meram Medical Faculty, Konya, Turkey

Objective Our purpose was to determine mortality and morbidity rates and selected outcome variables for infants especially weighing less than 1500 grams, who were admitted to the neonatal intensive care unit of our hospital from January 2007 to December 2008.

Material and Methods We evaluated infants who were admitted to the neonatal intensive care unit of our hospital (Konya University, Meram Medical Faculty) from January 2007 to December 2008. Results The percent of VLBW admissions to the our NICU was $14.3 \%$ in 2007 and $17.4 \%$ in 2008 . The mean birth weight and gestational age of the infants were 1027 \pm 308 grams (min-max: 400-1470gr), 28.3 \pm 3.8 weeks (min-max:22-36weeks) in 2007, 998 \pm 309 grams (min-max:400-1490gr), 28.4 \pm 3.4 weeks (minmax:22-36weeks) in 2008, respectively. Overall survival rate was $50 \%$ during two years. Respiratory support were given to $65 \%$ and 69.4\% VLBW newborns, in 2007 and 2008, respectively. Among selected outcomes, bronchopulmonary dysplasia, retinopathy of prematurity $(\mathrm{ROP})$, severe intraventricular hemorrhage (IVH), nosocomial infection, necrotizing enterocolitis(NEC), respiratory distress syndrome (RDS) were encountered in $1.66 \%, 4.6 \%, 1.9 \%$, $10.8 \%, 1.2 \%, 16.3 \%$ of the premature infants during two years, respectively.

Conclusion As a result the majority of neonatal deaths were due to complications of premature labor. Scientific and technological advances in Neonatology have led to increased rates of survival and long term morbidities in very low birth weight infants. Prevention of premature labor, sufficient antenatal maternal care and establishment of good delivery conditions to decrease neonatal infections and medical care after delivery could help to decrease neonatal mortality rates.

\section{PERINATAL MORTALITY RATE OF SELÇUK ÜNIVERSITY FACULTY OF MEDICIN IN YEAR OF 2008}

doi:10.1136/archdischild-2012-302724.1368

${ }^{1} \mathrm{H}$ Altunhan, ${ }^{2} \mathrm{~A}$ Annagür, ${ }^{3} Y U ̈$ Özdemir, ${ }^{3} \mathrm{M}$ Konak, ${ }^{3} \mathrm{R}$ Örs. ${ }^{1}$ Department of Neonatology, Abant lzzet Baysal University, Medical Faculty, Bolu; '2Department of Neonatology, Selcuk University, Selcuklu Medical Faculty; ${ }^{3}$ Department of Neonatology, Konya University, Meram Medical Faculty, Konya, Turkey

Objective Our purpose was to determine the perinatal mortality rate of our hospital in 2008. 